\title{
Diagnosis of tuberculosis from smear-negative presumptive TB cases using Xpert MTB/Rif assay: a cross-sectional study from Nepal
}

Priyatam Khadka ( $\sim$ khadka.priyatam@gmail.com )

Tribhuvan University Teaching Hospital https://orcid.org/0000-0002-1525-8130

Januka Thapaliya

Tribhuvan University - Trichandra Multiple Campus

Ramesh Bahadur Basnet

Tribhuvan University Teaching Hospital

Gokarna Raj Ghimire

National Tuberculosis Center, Nepal

Jyoti Amatya

Tribhuvan University - Trichandra Multiple Campus

\section{Basista Parsad Rijal}

Tribhuvan University Teaching Hospital

Research article

Keywords: Xpert MTB/Rif assay, Mycobacterium tuberculosis, Line Probe Assay, MDR-TB, smear-negative

Posted Date: October 18th, 2019

DOI: https://doi.org/10.21203/rs.2.13972/v2

License: (1) This work is licensed under a Creative Commons Attribution 4.0 International License.

Read Full License

Version of Record: A version of this preprint was published at BMC Infectious Diseases on December 1st, 2019. See the published version at https://doi.org/10.1186/s12879-019-4728-2. 


\section{Abstract}

Background In most developing countries, smear-negative pulmonary TB (SNPT) often gets missed from the diagnosis of consideration, though it accounts $30-65 \%$ of total PTB cases, due to deficient or inaccessible molecular diagnostic modalities. Methods The cross-sectional study enrolled 360 patients with clinical-radiological suspicion of SNPT in Tribhuvan University Teaching Hospital (TUTH). The patient selection was done as per the algorithm of Nepal's National Tuberculosis Programme (NTP) for Xpert MTB/RIF testing. Participants' demographic and clinical information were collected using a pretested questionnaire. The specimens were collected, processed directly for Xpert MTB/RIF test according to the manufacturer's protocol. The same samples were stained using the Ziehl-Neelsen technique then observed microscopically. Both findings were interpreted; rifampicin-resistant, if obtained, on Xpert testing was confirmed with a Line Probe Assay. Result Of 360 smear-negative sputum samples analyzed, $85(23.61 \%)$ found positive while $3(0.8 \%)$ of them were rifampicin resistance. The infection was higher in males, i.e. $60(25.3 \%$ ) compared to female $25(20.3 \%)$. The age group, $>45$ (nearly $33 \%$ ) with median age $42 \pm 21.5$, were prone to the infection. During the study period, $4.6 \%(515 / 11048)$ sputum samples were reported as smear-positive in TUTH. Consequently, with Xpert MTB/RIF assay, the additional case $16.5 \%$ $(n=85 / 515)$ from smear-negative presumptive TB cases were detected. Among the most occurring clinical presentations, cough and chest pain were positively associated with SNPT. While upper lobe infiltrates (36.4\%) and pleural effusion (40.4\%) were the most peculiar radiological impression noted in PTB patient. 94 multi-drug resistant(MDR) suspected cases were enrolled; of total suspects, 29(30.8\%) samples were rifampicin sensitive, $1(1.06 \%)$ indeterminant, 3(3.19\%) rifampicin-resistant while remaining of them were negative. 2(2.2\%) MDR cases were recovered from the patient with a previous history of ATT, of total 89 previously treated cases enrolled However, a single rifampicin-resistant from the new suspects. Conclusion With an application of the assay, the additional cases, missed with smear microscopy, could be sought and exact incidence of the diseases could be revealed. Keywords: Xpert MTB/Rif assay, Mycobacterium tuberculosis, Line Probe Assay, MDR-TB, smear-negative

\section{Background}

Tuberculosis is a treatable and curable disease (if early diagnosis of etiology and its drug resistance status could be made) but has been existing as a major public-health-threat around the globe(1). The reasons behind this unyielding infection are due to inaccessible or lacking diagnostic tool which carries higher precision and over-relying on clinical presentations, chest radiography and/or sputum smear microscopy-in most health centers of developing countries(2)(3)(4). As an air-borne infection, TB in one hemisphere ultimately relocates to others. Billions of dollars are being spent in developed nations; however, is worthless and these nations could not skip alone from the infection. The expanses could be fructiferous only if interrupting transmission chains from developing nations could be possible. For which, developing nations should be boosted with the collaborative support (financial and technological support) from developed nations. 
Globally, 10.4 million people get infected with TB, of which 41\% were from South East Asia. Turning to Nepal, nearly half of the population is infected with tuberculosis. About Nepal's National TB Program (NTP) report in 2015/16, 32,056 presumed cases were registered where $75 \%$ of them were bacteriologically confirmed as Mycobacterium tuberculosis(5). It has been estimated, each year, approximately 166 per 100,000 population develop TB, 5,000-7,000 death reported, and 8000-10,000 cases are predicted of being missed(5). In most developing countries due to deficient or inaccessible molecular diagnostic modalities, SNPT often gets missed from the diagnosis of consideration-though it accounts for $30-65 \%$ of total PTB cases(6)(7). Hence, tracing and treating these cases could be an auxiliary for reducing the global burden.

To address this burgeoning threat, world health organization (WHO) endorsed Xpert MTB/RIF assay as an accurate, feasible, rapid, affordable, and near-point-care TB diagnostic test for resource-limited settings of developing countries in December 2010. As collaborative efforts of global fund and NTP, Nepal the test was made available, for all patients requiring the test, in absolutely free of cost. However, only limited health centers provide this facility since fund circulation in every public hospital is yet to be done, and public-private health center's partnership is yet to be established, for making the test accessible to needful.

The study was aimed to diagnose tuberculosis from smear-negative presumptive PTB cases using Xpert MTB/RIF assay.

\section{Materials And Methods}

\section{Study design and settings}

A cross-sectional study was conducted among smear-negative but presumptive TB patients. The study was conducted at TUTH, the largest public hospital in Nepal, between $13^{\text {th }}$ April $2016-14^{\text {th }}$ April 2017. This is the only hospital where patients from the whole nation (with any economic class) come for treatment due to its' best-health-care facilities and super-specialty-care at an affordable cost. Before the introduction of Gene Xpert, the laboratory setting of this hospital was limited with AFB smear microscopy and Mycobacterium tuberculosis (MTB) culture but no drug susceptibility test (DST) facility. After then, with an aid of Global Fund and NTP the diagnostic test was made accessible as cost free services for all patients meeting algorithms set by NTP: presumptive PTB cases with abnormal chest X-ray, people living with HIV/AIDS (PLHA), treatment failure or previously treated cases and MDR suspects (Additional file 1).Only those eligible patients were selected for the study.

For the estimation of actual SNPT cases in one year, the smear-microscopy result over the study period was extracted from the laboratory record file where $4.66 \%$ (515/11048) positive cases were recorded.

Participants' demographic and clinical information were collected using a pre-tested questionnairewritten in the local language. The clinical evaluation and classification as MDR-TB cases were done by an expert chest physician; chest $\mathrm{X}$-ray features were classified as per radiologist reports. The patient with 
abnormal chest X-ray (upper lobe infiltrates, pleural effusion, diffuse infiltrates, cavitary lesions, other infiltrates, consolidation, other abnormalities) and having clinical presentations: persistent cough ( $\geq 2$ weeks), fever, drenching night sweats, weight loss ( $>1.5 \mathrm{~kg}$ in a month), loss of appetite, malaise, and shortness of breath or chest pain; were presumed as PTB. However, as MDR-TB, based on the smear results, previous treatment history, and no clinical improvement in response to the ATT (anti-tubercular therapy) after two months.

\section{Inclusion and exclusion criteria}

All smear-negative presumptive TB cases, either from previously treated cases or new suspects, and MDR suspects were enrolled. All positive cases diagnosed with smear microscopy were excluded, however. During our study period, 3 HIV positive patients were registered; nevertheless, not included in our study since all of them had smear-positive sputum.

\section{Xpert MTB/RIF assay and MDR confirmation}

All the procedures for gene Xpert testing were followed as per the manufacturers' specifications and guidelines(8). In brief, $0.5 \mathrm{ml}$ of expectorated sputum sample and Xpert sample reagent (SR) was added in the ratio $1: 2$ and was vortexed twice with 15 minutes incubation at room temperature until the sample gets emulsified completely. After then, $2 \mathrm{ml}$ of the mixture was transferred to Xpert test cartridge; the cartridge was then loaded into Xpert machine. Gene Xpert DX system, interprets the results, from measured fluorescent signals and display automatically either MTB complex detected, not detected, or rifampicin-resistant (if present) only after $90 \mathrm{mins}$.

Cases of rifampicin-resistance detected by Xpert were confirmed in the NTC Laboratory using MTBDR plus line probe assay (Hain Life science Germany) as per the manufacturers' instructions. In brief, bacterial DNA presumed as Rif resistant from sputum sample was extracted using cetyl-trimethyl ammonium bromide (CTAB) method which was then amplified, purified and hybridized with strips of MDRTB plus. The evaluation and interpretation of the results were done as per the interpretation chart provided with the kit.

\section{Data management and analysis}

The data obtained was entered in Microsoft Office Excel 2007 and analyzed by Statistical Package for Social Sciences (SPSS) version 16.0. Frequencies and percentages were calculated, and the odds ratio and nominal $95 \%$ confidence intervals (Cls) were presented for elucidating the association between variables. A two-sided $p$-value $<0.05$ was considered significant for all analyses. The sample size calculation was based on the prevalence rate (241 per 100000 population) in Nepal(4)(5). We estimated the sample size of 281 at $95 \%$ confidence level.

\section{Results}


A total of 360 smear-negative sputum samples (including 237 male and 123 female clinically suspected pulmonary tuberculosis patients) were tested with Xpert MTB/RIF assay. Among enrolled smear-negative cases, $85(23.61 \%)$ were positive PTB; where $3(0.8 \%)$ rifampicin resistance cases observed (Fig.1). The infection was higher in males, i.e. $60(25.3 \%)$ compared to female $25(20.3 \%)$. The age group, $>45$ (nearly $33 \%$ ) and below $15(20 \%)$ years, with median age $42 \pm 21.5$, found prone to the infection. The higher percentage of new suspects $63(23.5 \%)$ found positive on gene Xpert testing compared to previously treated cases 20(22.5\%) while highest was among loss to follow up 2(66.6\%) (Table1).

During the study period, 4.6\% (515/11048) sputum samples were reported as smear-positive in TUTH. Our study sum-up the additional case of pulmonary tuberculosis i.e. $16.5 \%(n=85 / 515)$, which were missed on the smear-microscopy.

\section{Clinical presentations}

Among the most occurring clinical presentations, cough and chest pain were more evident in SNPT cases and are significantly associated too. However, other clinical presentations: fever, weight loss, and night sweat found as non-specific presentations. (Table-2)

\section{Radiological impression on chest X-ray}

Of the total enrolled patient, 345 were presented with an abnormal radiological impression on chest X-ray while 15 of them had normal findings. Excluding patients with normal radiological findings, $23.38 \%$ $(n=83 / 355)$ with abnormal chest X-rays had acquired PTB. The upper lobe infiltrates $(36.4 \%)$ and pleural effusion (40.4\%) were evident in PTB patient; nevertheless, other impressions, like hilar/mediastinal lymphadenopathy (19.2\%), cavitary lesion (15.6\%), diffuse infiltration (12.2\%), segmental/lobar consolidation (3.2\%), were also noted. However, these impressions were not statically significant. (Table3)

\section{MDR case findings with Gene Xpert and its' confirmation}

94 MDR presumptive cases were enrolled. Among them, 29(30.8\%) samples were rifampicin sensitive, $1(1.06 \%)$ indeterminant, $3(3.19 \%)$ rifampicin-resistant while remaining of them were negative. $2(2.2 \%)$ MDR cases were recovered from the patient with a previous history of ATT, of total 89 previously treated cases enrolled while a single case from the new suspects.

MDR confirmation was done with Line Probe Assay where distinct bands revealing the genomic sequences i.e. TUB(+), rpoBWT(-), rpoBMUT(+), kat GWT(-), kat GMUT(+) ,inhAWT(+) , inhAMUT(-); RMP(resistant), INH(resistant) was observed(Fig.2)

\section{Discussion}

SNPT often gets missed from the diagnosis of consideration-particularly in developing countries like Nepal-though it accounts $30-65 \%$ of total PTB cases(7)(6). With this backdrop, the study was conducted 
to discover the actual incidence of PTB among presumptive cases which was not done before in Nepal. The application of Xpert MTB/RIF assay, in our setting, substantially increases the confirmed PTB cases. During our research period, $4.6 \%$ smear-positive PTB cases were reported at TUTH while upon execution of gene Xpert as a diagnostic tool, the rate surged to $16.5 \%(n=85 / 515)$. Our study is consistent with other studies, conducted in developing countries, which have suggested the benefit of Xpert in smear-negative patients(9)(10)(11)(12).

We aimed to include all presumptive cases, the infective forms i.e. PTB and tries to break the transmission chain with speedy diagnosis as far as possible. Hence, we opted for the Xpert MTB/RIF assay. In most, research studies and meta-analysis performed to this date, higher specificity of the test up to $99 \%$ has been observed on sputum samples(13)(14)(15)(10). Since, our study was not an evaluation, comparisons and implementation testing of gene Xpert assay against other diagnostic tests, limited studies found conducted in Nepal encompassing like our rationale(4).

In our study, we compare, likely occurring clinical features present in PTB patients with that gene Xpert results in SNPT cases. The only clinical feature to show a statistically significant difference between the groups was cough and chest pain. As portrayed with the latest meta-analysis and perspectives study where the sensitivity of cough as a positive predictive PTB ranges from $79.9 \%$ to $82 \%$ (16)(17). Hence, these clinical features could be one of the triaging features in optimizing the test where gene Xpert was not accessible to anyone-particularly in low-income-countries.

The cost expense of the test is another tethering truth with which the developing countries are being suffering. In most developing countries, the limited public hospital (covered with Global Fund) provides gene Xpert testing facility owing to expensive test cartridge and running cost which is nearly impossible for private health centers to afford. The test accessibility to every patient is the fundamental right and should be guaranteed by every nation. Therefore, government policy with a public-private partnership for the infection eradication is obligatory.

Ironically, in Nepal as NTP, with a policy to economize cost per cartridge on par to patient's number and also to make accessible on targeted population, had endorsed a guideline for the test. Patient with abnormal chest X-ray, presumed MDR patient, people living with HIV/AIDS (PLHA) and those with treatment failure cases were eligible for the test as described in the method section. Relying upon the guideline, we included the chest $X$-ray as a triaging test. In our study, common radiological findings evident in positive cases were upper lobe infiltrates (36.4\%) and pleural effusion (40.4\%). A similar study was conducted in our nearby hospital and neighboring country(India) where upper-lobe infiltrates and cavitary lesions were the common features(4)(18). Further, as to extrapolate the role of X-ray in PTB diagnosis, we compared the relationship between abnormal impressions vs. positive cases. We found, $23.38 \%$ of patients with abnormal chest X-ray had acquired PTB while Dutta et al. reported $34.4 \%$ in patients with similar features (18).

Although, higher percentage of new suspects 63(23.5\%) found positive on Gene Xpert testing compared to previously treated cases $20(22.5 \%) ; 2(2.2 \%)$ MDR cases were recovered from the patient with a 
previous history of ATT, of total 89 previously treated cases enrolled. However, a small population of previously-treated case was included in our study, the findings portrayed similar view of resistance-trend as surveyed in 1992-1993 in the Western Cape Province where 8.6\% acquired and 3.2\% initial drug resistance was noted in among these patients (19). In another studies, the highest in range from 15$27.7 \%$, MDR-TB was found to be associated in previously treated cases, however(20)(21). Furthermore, the previously treated patients may be at high risk of extensively drug-resistant(XDR)TB too (19). Hence, the clinicians must be cautious in treating the previously treated cases.

Of total positive cases, 3.5\% ( $n=3)$ were valid rifampicin-resistant (confirmed with Line probe assay); no false-positive rifampicin resistance was noted as reported in different literature with gene Xpert testing(15)(13)(22)(23). Round the globe, about one-third of the countries had surveyed on the incidence of MDR-TB which was in between $2-14 \%(24)(25)(26)$; our findings coincide within this range.

For improving patient care and abbreviating the disease transmission chain, speedy detection of tuberculosis and its drug-resistance with precision is crucial. In this perspective, endorsing gene Xpert as a diagnostic tool by WHO is the commendable action in curbing the global threat to some extent. Further, a long-distance yet to be traveled: making it more accessible, affordable, and upgrading sensitivity of Xpert MTB/RIF assay also covering disseminated TB. Only then billions of dollars expended could be a wise investment.

\section{Limitations}

Inability to include large samples was the major drawback of our study. Additional SNPT cases could be still missing from our study frame since is the test is not of absolute accuracy. Also, we could not run the phenotypic DST and Line Probe assay for all Xpert MTB/RIF positive specimens. If it was possible, clear MDR status could be traced which might be missed even from Xpert MTB/RIF assay.

\section{Conclusion}

For improving patient care and abbreviating the disease transmission chain, speedy detection of tuberculosis and its drug-resistance with precision is crucial. For which, gene Xpert MTB/RIF assay would be a proper option. With an application of the assay, the additional cases, missed with smear microscopy, could be sought and exact incidence of the diseases could be revealed. Further, the implementation of the test, in every developing country, if possible, could be a wise investment in restricting the global burden, as targeted by $\mathrm{WHO}$.

\section{Declarations}

\section{Authors' contributions}

PK conceived the study, design the manuscript, review of the literature. RBB, JT, GPR, and JA, reviewed the manuscript and gave the concept of the research paper. BPR critically reviewed the manuscript. All 
authors read and approved the manuscript.

\section{Acknowledgments}

We would like to thanks Dr. Kedar Narshing KC (Medical Director of NTC) for his tremendous technical support and permission for data uses.

\section{Competing interest}

The authors declare that they have no competing interests.

\section{Availability of data and materials}

Data generated or analyzed during this study are included in this manuscript and remaining are available from the corresponding author on reasonable request.

\section{Consent to publish}

Not applicable.

\section{Ethics approval and consent to participate}

This research was approved by the Institutional Review Committee of the National Tuberculosis Center and Trichandra Multiple Campus, Nepal. Permission from NTP authorities was obtained before the study was conducted; written informed consent was taken from all patients or their parents before participating in the study. Data regarding personal information and infectious disease were coded and kept confidential.

\section{Funding}

Not applicable (Nil)

\section{References}

1. World Health Organization. Global Tuberculosis Report 2017: Leave no one behind - Unite to end TB [Internet]. 2017. 146 p. Available from: http://www.who.int/tb/publications/global_report/gtbr2017_main_text.pdf?ua=1

2. Pandey P, Pant ND, Rijal KR, Shrestha B, Kattel S, Banjara MR, et al. Diagnostic Accuracy of GeneXpert MTB / RIF Assay in Comparison to Conventional Drug Susceptibility Testing Method for the Diagnosis of Multidrug-Resistant Tuberculosis. 2017;8-13.

3. World Health Organization. Policy statement: automated real-time nucleic acid amplification technology for rapid and simultaneous detection of tuberculosis and rifampicin resistance: In: MTB/RIF, WHO Policy Xpert,Xpert MTB/RIF system WHO/HTM/TB/20114 Geneva; 2011. 
4. Shrestha P, Arjyal A, Caws M, Prajapati KG, Karkey A, Dongol S, et al. The Application of GeneXpert MTB / RIF for Smear-Negative TB Diagnosis as a Fee-Paying Service at a South Asian General Hospital. Tuberc Res Treat [Internet]. 2015;2015:6. Available from: http://dx.doi.org/10.1155/2015/102430

5. National Tuberculosis Programme Nepal, Annual report 2016 [Internet]. Thimi, Bhaktapur: Government of Nepal Ministry of Health Department of Health Services National Tuberculosis Center; 2016. Available from: https://nepalntp.gov.np/?view=publication

6. De Queiroz Mello FC, Do Valle Bastos LG, Machado Soares SL et al. Predicting smear negative pulmonary tuberculosis with classification trees and logistic regression: A cross-sectional study. BMC Public Health. 2006;6:1-8.

7. Campos LC, Vieira Rocha MV, Cunha Willers DM et al. Characteristics of patients with smear-negative pulmonary tuberculosis (TB) in a region with high TB and HIV prevalence. PLoS One. 2016;11(1):18.

8. Cephid, 2015, Sunnyvale C 94089-1189, USA. Xpert® MTB/RIF Assay, GXMTB/-US-10. 2015; Available from: xpert-mtb-rif-english-package-insert-301-1404-rev-b-february-2015.pdf

9. D. W. Dowdy, A. Cattamanchi, K. R. Steingart et al. "Is scale-up worth it? Challenges in economic analysis of diagnostic tests for tuberculosis,." PLoS Med [Internet]. 2011;8, no. Available from: https://doi.org/10.1371/journal.pmed.1001063

10. K. R. Steingart, H. Sohn IS et al. "Xpert MTB/RIF assay for pulmonary tuberculosis and rifampicin resistance in adults,." Cochrane Database Syst Rev vol 1, [Internet]. Available from: Article ID CD009593, 2014. View at Publisher $\cdot$ View at Google Scholar

11. Rachow A, Zumla A, Heinrich N, Rojas-ponce G, Mtafya B, Ntinginya EN, et al. Rapid and Accurate Detection of Mycobacterium tuberculosis in Sputum Samples by Cepheid Xpert MTB / RIF Assay - A Clinical Validation Study. 2011;6(6):1-8.

12. Friedrich SO, Rachow A, Saathoff E, Singh K, Mangu CD, Dawson R, et al. Assessment of the sensitivity and specifi city of Xpert MTB / RIF assay as an early sputum biomarker of response to tuberculosis treatment. Lancet Respir [Internet]. 2013;1(6):462-70. Available from: http://dx.doi.org/10.1016/S2213-2600(13)70119-X

13. Lawn SD NM. "Xpert MTB/RIF assay: development, evaluation and implementation of a new rapid molecular diagnostic for tuberculosis and rifampicin resistance,." Future Microbiol. 2011;6(9):106782.

14. Boehme CC, Nicol MP, Nabeta P, Michael JS, Gotuzzo E, Tahirli R, et al. Feasibility, diagnostic accuracy, and eff ectiveness of decentralised use of the Xpert MTB / RIF test for diagnosis of tuberculosis and multidrug resistance: a multicentre implementation study. Lancet [Internet]. 2011;377(9776):1495-505. Available from: http://dx.doi.org/10.1016/S0140-6736(11)60438-8

15. Vassall A, Kampen S Van, Sohn H, Michael JS, John KR, Boon S Den, et al. Rapid Diagnosis of Tuberculosis with the Xpert MTB / RIF Assay in High Burden Countries: A Cost-Effectiveness 
Analysis. PLoS Med [Internet]. 2011;8(11). Available from:

https://doi.org/10.1371/journal.pmed.1001120

16. H. Getahun, W. Kittikraisak, C. M. Heilig et al. "Development of a standardized screening rule for tuberculosis in people living with HIV in resource-constrained settings: individual participant data meta-analysis of observational studies,." PLOS Med vol 8, no 1, Artic ID e1000391, 2011.

17. Menberu MA. Performance of the WHO 2011 TB Symptom Screening Algorithm for Pulmonary TB Diagnosis among HIV-Infected Patients in Gondar University Referral Hospital, Ethiopia. Int J Microbiol [Internet]. Available from: http://dx.doi.org/10.1155/2016/9058109

18. Datta B, Hazarika A, Shewade HD, Ayyagari K et al. Digital chest X - ray through a mobile van: public private partnership to detect sputum negative pulmonary TB. BMC Res Notes. 2017;2-5.

19. den Boon S, van Lill SW, Borgdorff MW et al. High Prevalence of Tuberculosis in Previously Treated Patients, Cape Town, South Africa. Emerg Infect Dis. 2007;3(8):1189-1194.

20. Zignol M, Wright A, Jaramillo E, Nunn P, Raviglione MC et al. Patients with Previously Treated Tuberculosis No Longer Neglected. Clin Infect Dis. 2007;44(1):61-4.

21. Forson A, Kwara A, Kudzawu S, Gehre, Florian et al. A cross-sectional study of tuberculosis drug resistance among previously treated patients in a tertiary hospital in Accra, Ghana: Public health implications of standardized regimens. BMC Infect Dis. 2018;18(1):4-9.

22. Nathavitharana RR, Cudahy PG, Schumacher SG, Steingart KR, Pai M et al. Accuracy of line probe assays for the diagnosis of pulmonary and multidrug-resistant tuberculosis: A systematic review and meta-analysis. Eur Respir J. 2017;49(1).

23. Rufai SB, Kumar P, Singh A, Prajapati S, Balooni V, Singh S. Comparison of xpert MTB/RIF with line probe assay for detection of rifampin-monoresistant mycobacterium tuberculosis. J Clin Microbiol. 2014;52(6):1846-52.

24. Adegboyega T.T, Thomas B.T., Agu G. C. AA. Can Nigeria Sustain the Fight against Drug Resistant Mycobacterium tuberculosis? J Microbiol Res. 2014;4(2):72-7.

25. Jahan H, Jhora ST, Habib ZH, Yusuf A. Diagnostic Evaluation of GeneXpert MTB / RIF Assay for the Detection of Rifampicin Resistant Mycobacterium tuberculosis among Pulmonary Tuberculosis Patients in Bangladesh. 2016;(March):55-60.

26. Singh G G, Takkar, J et al. Recent Advances in Multi-Drug-Resistant Tuberculosis and RNTCP. Indian J community Med. 2008;(33(4)):219-223.

\section{Tables}




\begin{tabular}{|c|c|c|c|c|c|c|}
\hline $\begin{array}{l}\text { Patients } \\
\text { demograph } \\
\text { ics }\end{array}$ & $\begin{array}{l}\text { smear-negative PTB not detected } \\
\text { with Xpert MTB/RIF assay(\%) }\end{array}$ & $\begin{array}{c}\text { smear-negative PTB } \\
\text { detected with MTB/RIF } \\
\text { assay(\%) }\end{array}$ & Total & OR & $\begin{array}{c}95 \% \\
\mathrm{Cl}\end{array}$ & $\begin{array}{l}P \\
\text { value }\end{array}$ \\
\hline \multicolumn{7}{|l|}{ Gender } \\
\hline Male & $177(74.7)$ & $60(25.3)$ & 237 & \multirow[t]{2}{*}{1.33} & \multirow{2}{*}{$\begin{array}{l}0.78- \\
2.5\end{array}$} & \multirow[t]{2}{*}{0.29} \\
\hline Female & 98(79.6) & $25(20.3)$ & 123 & & & \\
\hline \multicolumn{7}{|l|}{ Age group } \\
\hline$<14$ year & $36(80)$ & $9(20)$ & 45 & - & - & - \\
\hline & 65(89.9) & $8(10.1)$ & 73 & & & \\
\hline years & & & & 0.5 & $\begin{array}{l}0.21- \\
1.39\end{array}$ & 0.2 \\
\hline \multicolumn{7}{|l|}{30 to 44} \\
\hline years & $62(81.6)$ & 14(18.4) & 76 & & & \\
\hline 45 to 59 & $53(67.9)$ & $25(32.1)$ & 78 & & & \\
\hline years & & & & 0.95 & $\begin{array}{l}0.50- \\
1.84\end{array}$ & 0.93 \\
\hline$>60$ years & $59(66.3)$ & $29(33.7)$ & 88 & & & \\
\hline \multicolumn{7}{|c|}{ Clinical history } \\
\hline \multirow{2}{*}{$\begin{array}{l}\text { New } \\
\text { suspects }\end{array}$} & 205(76.5) & $63(23.5)$ & 268 & & & \\
\hline & & & & 1.06 & $\begin{array}{l}0.59- \\
1.87\end{array}$ & 0.84 \\
\hline \multirow[t]{2}{*}{$\begin{array}{l}\text { Previously } \\
\text { treated }\end{array}$} & & & & & & \\
\hline & $69(77.5)$ & $20(22.5)$ & 89 & & & \\
\hline $\begin{array}{l}\text { Loss-to- } \\
\text { follow up }\end{array}$ & $1(33.4)$ & $2(66.6)$ & 3 & - & - & - \\
\hline
\end{tabular}




\begin{tabular}{|c|c|c|c|c|c|c|c|}
\hline \multicolumn{2}{|c|}{ Clinical presentation } & \multicolumn{2}{|c|}{ Result of gene Xpert MTB/Rif } & \multirow[b]{2}{*}{ Total } & \multirow[b]{2}{*}{ Odds ratio } & \multirow[b]{2}{*}{$95 \% \mathrm{Cl}$} & \multirow[b]{2}{*}{$P$ value } \\
\hline Clinical pre & ation & $\begin{array}{l}\text { Not detected } \\
(\%)\end{array}$ & Detected (\%) & & & & \\
\hline \multirow{2}{*}{ Fever } & $\mathrm{Y}$ & $207(74.7)$ & $70(25.3)$ & 277 & \multirow{2}{*}{1.5} & \multirow{2}{*}{$0.82-2.85$} & \multirow{2}{*}{0.17} \\
\hline & $\mathrm{N}$ & $68(81.9)$ & 15(18.1) & 83 & & & \\
\hline \multirow{2}{*}{ Cough } & Y & $242(74.7)$ & $82(25.3)$ & 324 & \multirow{2}{*}{3.7} & \multirow{2}{*}{$1.11-12.48$} & \multirow{2}{*}{0.03} \\
\hline & $\mathrm{N}$ & $33(91.7)$ & $3(8.3)$ & 36 & & & \\
\hline \multirow{2}{*}{ Weight loss } & $\mathrm{Y}$ & $229(76.1)$ & $72(23.9)$ & 301 & \multirow{2}{*}{1.1} & \multirow{2}{*}{$0.57-2.17$} & \multirow{2}{*}{0.75} \\
\hline & $\mathrm{N}$ & $46(78.0)$ & $13(22)$ & 59 & & & \\
\hline \multirow{2}{*}{ Chest pain } & $\mathrm{Y}$ & $87(59.1)$ & $60(40.9)$ & 147 & & \multirow{2}{*}{$3.05-8.82$} & \multirow{2}{*}{0.001} \\
\hline & $\mathrm{N}$ & 188(88.2) & $25(11.8)$ & 213 & 5.2 & & \\
\hline Night & Y & $146(76.0)$ & $46(24)$ & 192 & \multirow{2}{*}{1.04} & \multirow{2}{*}{$0.64-1.7$} & \multirow{2}{*}{0.86} \\
\hline sweat & $\mathrm{N}$ & $129(76.8)$ & $39(23.2)$ & 168 & & & \\
\hline
\end{tabular}

Table-3: Characterization of PTB cases in terms of clinical presentation chest X-ray features

\begin{tabular}{lccc}
\hline Features on chest X-ray & \multicolumn{2}{c}{ Result of Xpert MTB/Rif assay } & \multirow{2}{*}{ Total(n) } \\
\cline { 2 - 3 } & Not detected (\%) & Detected (\%) & \\
\hline Upper lobe infiltrate & $70 \mathrm{a}(63.6)$ & $40 \mathrm{~b}(36.4)$ & 110 \\
Pleural effusion & $34 \mathrm{a}(59.6)$ & $23 \mathrm{~b}(40.4)$ & 57 \\
\hline Hilar /mediastinal lymphadenopathy & $21 \mathrm{a}(80.8)$ & $5 \mathrm{a}(19.2)$ & 26 \\
\hline Cavitary leision & $27 \mathrm{a}(84.4)$ & $5 \mathrm{a}(15.6)$ & 32 \\
\hline Normal & $13 \mathrm{a}(86.7)$ & $2 \mathrm{a}(13.3)$ & 15 \\
\hline Diffuse infilteration & $29 \mathrm{a}(87.9)$ & $4 \mathrm{a}(12.1)$ & 33 \\
\hline Abnormal & $51 \mathrm{a}(91.1)$ & $5 \mathrm{~b}(8.9)$ & 56 \\
\hline Segmental/lobar consolidation & $30 \mathrm{a}(96.8)$ & $1 \mathrm{~b}(3.2)$ & 31 \\
\hline Total Count & & & \\
\hline
\end{tabular}

*Each subscript letter denotes a subset of result of Xpert MTB /RIF test categories whose column proportions do not differ significantly from each other at the .05 level

\section{Additional File Legend}

Additional file-1: NTP algorithm of gene Xpert testing. 


\section{Figures}

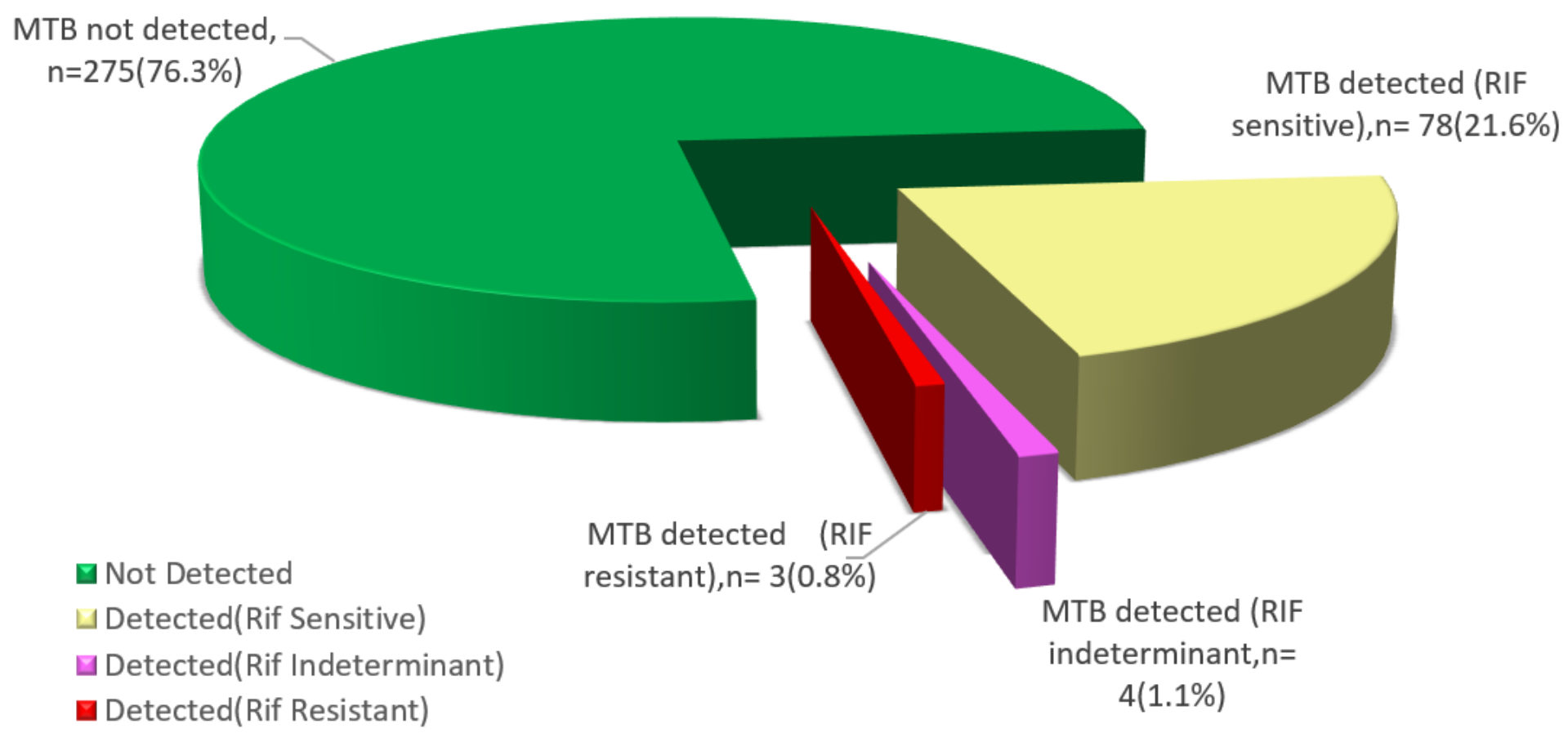

\section{Figure 1}

The total case detection of SNPT with Xpert MTB/RIF Assay is shown in the pie chart. Each portion of pie chart indicates the number/percentage of enrolled cases and their result. 


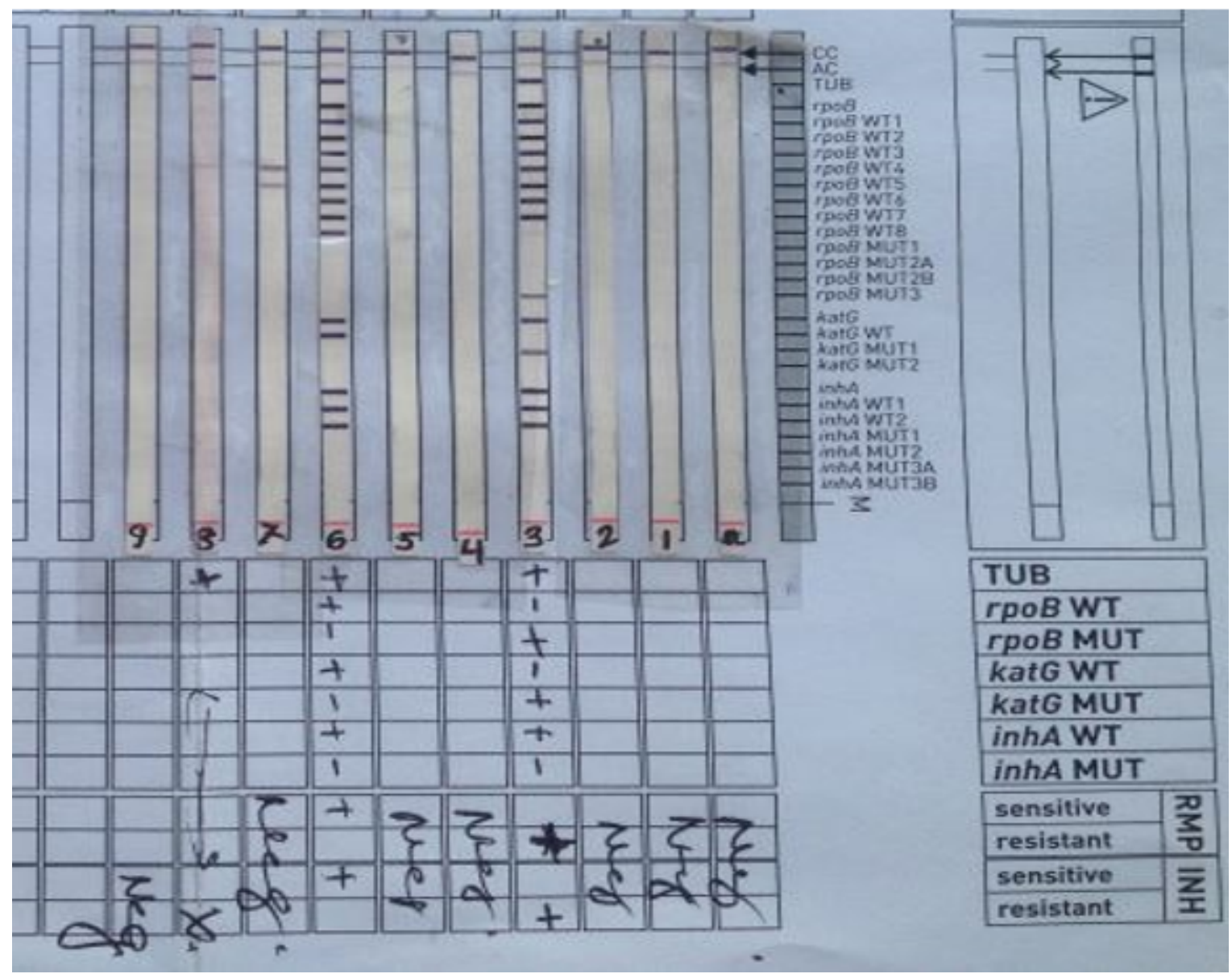

Figure 2

Line probe assay showing mutated genomic sequences.

\section{Supplementary Files}

This is a list of supplementary files associated with this preprint. Click to download.

- Algorithm.pdf 